INTERNATIONAL JOURNAL
OFE
PHARMACEUTICAL SCIENCES
RESEARCI

Received on 26 June 2018; received in revised form, 28 September 2018; accepted, 05 October 2018; published 01 March 2019

\title{
FORMULATION AND EVALUATION OF FLOATING GEL BEADS OF LORATADINE
}

Sk. Arifa Begum ${ }^{*}$, J. Jhansi ${ }^{2}$ and K. Padmalatha ${ }^{3}$

Department of Pharmaceutics ${ }^{1}$, Chalapathi Institute of Pharmaceutical Sciences, Lam, Guntur - 522034, Andhra Pradesh, India.

Department of Pharmaceutics ${ }^{2}$, Department of Pharmacology ${ }^{3}$, Vijaya Institute of Pharmaceutical Sciences for Women, Enikepadu, Vijayawada - 521108, Andhra Pradesh, India.

Keywords:

Floating,

Gel beads, Loratadine, Ionic gelation, Zero-order release

Correspondence to Author:

Sk. Arifa Begum

Associate Professor,

Department of Pharmaceutics,

Chalapathi Institute of Pharmaceutical

Sciences, Lam, Guntur - 522034,

Andhra Pradesh, India.

E-mail: arifashaik2007@gmail.com
ABSTRACT: A floating controlled drug delivery system of loratadine was formulated to enhance the retention time in the stomach and to modify the release characteristics of loratadine. Loratadine loaded floating gel beads were prepared by ionic gelation technique using different polymers such as HPMC K4M, HPMC K15M, and carbopol 934P in different proportions and sodium bicarbonate as the gas forming agent. FT-IR spectra revealed that there was no significant interaction of loratadine with the carriers and other excipients. The prepared beads were evaluated for particle size analysis, bulk density, tapped density, compressibility index, hausner's ratio, the angle of repose, swelling index, drug entrapment efficiency, \% yield, \% buoyancy of loratadine floating beads, in-vitro drug release studies, kinetic modeling of drug release and stability studies. Results of the in-vitro drug release study indicated sustained release of loratadine for up to $12 \mathrm{~h}$. The drug release kinetics of optimized formulation F7 was best fitted with the zero order and Peppas model with $n>0.45$.
INTRODUCTION: The oral route is increasingly being used for the delivery of therapeutic agents because the low cost of the therapy and ease of administration lead to high levels of patient compliance. More than $50 \%$ of the drug delivery systems available in the market are oral drug delivery systems ${ }^{1}$. A major drawback in oral controlled drug delivery is that not all drug candidates are absorbed uniformly throughout the GIT. Some drugs are absorbed only in a particular portion of GIT or are absorbed to a different extent in various segments of GIT.

\begin{tabular}{|l|c|}
\hline QUICK RESPONSE CODE & DOI: \\
\hline DOI link: http://dx.doi.org/10.13040/IJPSR.0975-8232.10(3).1289-99 \\
\hline
\end{tabular}

An absorption window exists because of physiological, physicochemical or biochemical factors. Recent scientific and patent literature reveals increased interest in novel dosage forms that can be retained in the stomach for a prolonged and predictable period.

One of the most feasible approaches is to control the gastric residence time using gastro-retentive dosage forms (GRDDS) that can provide newer therapeutic options. GRDDS can improve the controlled delivery of drugs by continuously releasing the drug for a prolonged period before it reaches its absorption site, thus ensuring its optimal bioavailability ${ }^{2}$. Loratadine is an antihistamine that reduces the effects of natural chemical histamine in the body. Histamine can produce symptoms of sneezing, itching, watery eyes, and runny nose. Loratadine is absorbed in the proximal part of the 
gastrointestinal tract; it is stable in acidic $\mathrm{pH}$, has a narrow therapeutic absorption window in the GIT and the presence of food enhances its bioavailability ${ }^{3}$, meeting the primary criterion for selection of loratadine as the drug candidate to be formulated as a floating multiple unit dosage forms.

The purpose of designing a floating multiple unit dosage forms is to develop a reliable formulation of loratadine that has all the advantages of a floating single unit dosage form but is devoid of disadvantages of single unit dosage forms, namely sticking to or being obstructed in the GIT. In spite of all sophisticated formulations, the retention time of the single unit floating drug delivery system (FDDS) depends on many physiological factors, and it is a well-known fact that early gastric emptying of a monolithic device causes rapid lack of therapeutic efficacy, especially with drugs having an absorption window only in the stomach 4 . The floating beads have been employed to make a sustained release of the drug in the stomach to decrease the dose of the drug and overcome its side effects. The common benefits of the floating beads were ease of preparation without the need for high temperature and a high percentage of the drug entrapment.

The present research was mainly focused on the development and evaluation of gastroretentive, multiple units and controlled release formulations of loratadine. Various batches of floating beads were prepared by ionotropic/emulsion gelation method using different polymers in different proportions to achieve the controlled release of drug from developed floating beads.

\section{MATERIALS AND METHODS:}

Materials: Loratadine was received as a gift sample from Granules India Ltd., Hyderabad, India. Sodium alginate and Calcium chloride were procured from Sd Fine-Chem Ltd., Mumbai. Hydroxypropyl methylcellulose (HPMC K4M \& 15M), Carbopol 934P were obtained from Rolex Chemical., Mumbai. Sodium bicarbonate was purchased from Quaikem Fine Chem Pvt. Ltd., Vadodara.

Methods: Drug - Carrier - Excipients Compatibility Checking: The drug and the excipients compatibility studies were carried out by checking the physical appearance as well as using
FT-IR spectral analysis. The compatibility studies were performed to ascertain any incompatibility of the drug with the excipients/ additives used in the formulation of floating gel beads of loratadine.

Fourier Transform Infra Red (FT-IR) Analysis:

5 An FT-IR spectrophotometer was employed for infrared analysis of the samples. Approximately 4$5 \mathrm{mg}$ of the sample was mixed with dry potassium bromide $(\mathrm{KBr})$, and the sample was analyzed at transmission mode over the $4000-400 \mathrm{~cm}^{-1}$ wavenumber range.

\section{Calibration of Standard Curve of Loratadine:} Preparation of Standard Graph of Loratadine in pH 1.2 Buffer: $100 \mathrm{mg}$ of loratadine was weight accurately and dissolved in $100 \mathrm{ml}$ of $\mathrm{pH} 1.2$ buffer in $100 \mathrm{ml}$ volumetric flask. The resulting solution had a concentration of $1 \mathrm{mg} / \mathrm{ml}(1000 \mu \mathrm{g} / \mathrm{ml})$. From the stock solution, $1 \mathrm{ml}$ was taken in a $10 \mathrm{ml}$ volumetric flask, and the volume was made up to $10 \mathrm{ml}$ with $\mathrm{pH} 1.2$ buffer (Secondary stock - 100 $\mu \mathrm{g} / \mathrm{ml})$. From the secondary stock solution, $0.5 \mathrm{ml}$, $1 \mathrm{ml}, 1.5 \mathrm{ml}, 2.0 \mathrm{ml}, 2.5 \mathrm{ml}$ and $3.0 \mathrm{ml}$ were taken and volume made up to $10 \mathrm{ml}$ with $\mathrm{pH} 1.2$ buffer to get concentrations of $5 \mu \mathrm{g} / \mathrm{ml}, 10 \mu \mathrm{g} / \mathrm{ml}, 15$ $\mu \mathrm{g} / \mathrm{ml}, \quad 20 \mu \mathrm{g} / \mathrm{ml}, \quad 25 \mu \mathrm{g} / \mathrm{ml}$ and $30 \mu \mathrm{g} / \mathrm{ml}$ concentrations, respectively. The absorbance of each solution was measured by UV - Visible spectrophotometer at $214 \mathrm{~nm}$ using a $\mathrm{pH} 1.2$ buffer as blank. The graph of concentration versus absorbance was plotted.

\section{Method of Preparation of Loratadine Floating} Gel Beads: Loratadine is floating gel beads were formulated using ionic gelation technique. $10 \mathrm{mg}$ of loratadine was dissolved in $5 \mathrm{ml}$ of purified water to prepare a loratadine solution. The prepared loratadine solution was added to $95 \mathrm{ml}$ of sodium alginate solution $(3 \%$ w/v) containing HPMC K4M / HPMC K15M / Carbopol 934P as polymers. Sodium bicarbonate was used as a gas forming agent and added to a sodium alginate solution in a ratio of $1: 1$.

The mixture was dropped into $100 \mathrm{ml}$ of calcium chloride solution $(1 \% \mathrm{w} / \mathrm{v})$ using $24 \mathrm{G}$ syringe needle. The beads formed in the solution were then agitated for $10 \mathrm{~min}$ to improve the rigidity of floating gel beads. The beads were collected and washed with purified water followed by drying for $48 \mathrm{~h}$. 
TABLE 1: FORMULATION OF LORATADINE FLOATING GEL BEADS

\begin{tabular}{cccccccc}
\hline Formula code & $\begin{array}{c}\text { Drug } \\
(\mathbf{m g})\end{array}$ & $\begin{array}{c}\text { Sodium } \\
\text { alginate }(\mathbf{g})\end{array}$ & $\begin{array}{c}\text { HPMC } \\
\text { K4M (g) }\end{array}$ & $\begin{array}{c}\text { HPMC } \\
\text { K15M }(\mathbf{g})\end{array}$ & $\begin{array}{c}\text { Carbopol 934P } \\
(\mathbf{g})\end{array}$ & $\mathbf{N a H C O}_{\mathbf{3}}(\mathbf{g})$ & $\mathbf{C a C l}_{\mathbf{2}}(\mathbf{g})$ \\
\hline F1 & 100 & 3 & - & - & - & 3 & 1 \\
F2 & 100 & 2 & 1 & - & - & 3 & 1 \\
F3 & 100 & 1.750 & 1.250 & - & - & 3 & 1 \\
F4 & 100 & 1.500 & 1.500 & - & - & 3 & 1 \\
F5 & 100 & 2 & - & 1 & - & 3 & 1 \\
F6 & 100 & 1.750 & - & 1.250 & - & 3 & 1 \\
F7 & 100 & 1.500 & - & 1.500 & - & 3 & 1 \\
F8 & 100 & 2.950 & - & - & 0.050 & 3 & 1 \\
F9 & 100 & 2.900 & - & - & 0.100 & 3 & 1 \\
F10 & 100 & 2.850 & - & - & 0.150 & 3 & 1 \\
F11 & 100 & 2.500 & 0.250 & 0.250 & - & 3 & 1 \\
F12 & 100 & 2.500 & - & 0.250 & 0.250 & 3 & 1 \\
\hline
\end{tabular}

\section{Evaluation of Loratadine Floating Gel Beads:} Particle Size Analysis: Average particle size of beads was determined using sieve analysis method. Twenty-gram beads were weighed carefully and placed on the first screen and shaken for a certain time. Each fraction is then taken and weighed. The experiment was performed in triplicate. The particle size was determined as follows:

$$
d_{a v e}=\Sigma n d / \Sigma n
$$

Where, $\mathrm{d}_{\mathrm{ave}}=$ Average diameter of beads; $\mathrm{n}=$ Percent of each fraction retained on each sieve and $\mathrm{d}=$ Arithmetic mean size of sieve opening.

\section{Flow Properties:}

Bulk Density $\left(\mathbf{D}_{\mathbf{b}}\right)$ : It is the ratio of the total mass of powder to the bulk volume of powder. It was measured by pouring the weighed powder (passed through standard sieve \# 20) into a measuring cylinder, and initial weight was noted this initial volume is called the bulk volume. From this, the bulk density was calculated according to the formula mentioned below. It is expressed in $\mathrm{g} / \mathrm{ml}$ and is given by,

$$
\mathrm{D}_{\mathrm{b}}=\mathrm{M} / \mathrm{V}_{\mathrm{b}}
$$

Where $\mathrm{M}$ is the mass of powder, $\mathrm{V}_{\mathrm{b}}$ is the bulk volume of the powder and $D_{b}$ is the bulk density of the powder.

Tapped Density $\left(\mathbf{D}_{t}\right)$ : It is the ratio of the total mass of the powder to the tapped volume of the powder. Volume was measured by tapping the powder for 750 times, and the tapped volume was noted if the difference between these two volumes is less than $2 \%$. If it is more than $2 \%$, tapping is continued for 1250 times, and tapped volume was noted. Tapping was continued until the difference between successive volumes is less than $2 \%$ (in a bulk density apparatus). It is expressed in $\mathrm{g} / \mathrm{ml}$ and is given by,

$$
\mathrm{D}_{\mathrm{t}}=\mathrm{M} / \mathrm{V}_{\mathrm{t}}
$$

Where $\mathrm{M}$ is the mass of powder and $\mathrm{V}_{\mathrm{t}}$ is the tapped volume of the powder.

Carr's Index (or) \% Compressibility Index: It indicates powder flow properties. It is expressed in percentage and is given by

$$
\text { Carr's Index }=\frac{\text { Tapped density }- \text { Bulk density }}{\text { Tapped density }} \times 100
$$

Hausner's Ratio: Hausner's ratio is an indirect index of ease of powder flow. It is calculated by the following formula,

$$
\text { Hausner's ratio }=\frac{\text { Tapped density }}{\text { Bulk density }}
$$

Lower Hausner's ratio $(<1.25)$ indicates better flow properties than higher ones $(>1.25)$

The angle of Repose: The frictional forces in loose powder or granules can be measured by angle of repose. This is the maximum angle possible between the surface of a pile of powder or granules and the horizontal plane. The granules were allowed to flow through the funnel fixed to a stand at definite height (h). The angle of repose was then calculated by measuring the height and radius of the heap of granules formed.

$$
\theta=\tan ^{-1}(\mathrm{~h} / \mathrm{r})
$$

Where, $\theta=$ angle of repose, $h=$ height of the heap and $\mathrm{r}=$ radius of the heap. 
Swelling Studies: Known weight $(50 \mathrm{mg})$ of floated beads was soaked in $100 \mathrm{ml}$ of buffer 1.2 $\mathrm{pH}$ at $37^{\circ} \mathrm{C} \pm 0.5^{\circ} \mathrm{C}$. Then the beads were removed at specified time intervals, dried and weighed to determine the swelling index ${ }^{6,7}$. Swelling index was determined from the following equation:

Swelling index $=\frac{\begin{array}{c}\text { The weight of swollen }-\begin{array}{c}\text { Initial weight of } \\ \text { beads }\end{array} \\ \text { beads }\end{array}}{\text { The initial weight of beads }} \times 100$

Percentage Drug Entrapment Efficiency: The encapsulation efficiency was determined from the following equation,

$\underset{\text { Entrapment Efficiency }}{\% \text { Drug }}=\frac{\text { The actual amount of drug }}{\text { The theoretical amount of drug }} \times 100$

Percentage Yield: Percentage yield for the formulated beads was calculated from the following ${ }^{8,9}$ :

$$
\text { Percentage yield }=\frac{\text { The weight of the beads }}{\text { The weight of drug }+ \text { Polymer weight }} \times 100
$$

Scanning Electron Microscopy (SEM) Studies: The prepared floated beads were examined for its surface morphology by SEM. The samples were fixed in individual stubs and coated uniformly with gold $^{8}$.

Percentage Drug Loading: $50 \mathrm{mg}$ of the loratadine prepared beads were weighed and dissolved in $50 \mathrm{ml}$ of $\mathrm{pH} 1.2$ buffer centrifuged, filtered and then the filtrate was analyzed at 214 $\mathrm{nm}$ using a UV/visible spectrophotometer (Lab India). The experiment was carried out in triplicate, and drug loading was calculated from the following equation:

$$
\text { Drug Loading }=\frac{\text { The weight of drug in beads }}{\text { Total weight of beads }} \times 100
$$

Buoyancy Study: In-vitro floating ability can be determined by calculating percentage buoyancy and performed in USP type II dissolution test apparatus by spreading the floating microspheres in $0.1 \mathrm{~N} \mathrm{HCl}$. The media is stirred at 100 revolutions per minute $(\mathrm{rpm})$ at $37 \pm 0.5{ }^{\circ} \mathrm{C}$. After specific intervals of time, both the fraction of microspheres (floating and settled microspheres) is collected, and buoyancy of the floating microspheres is determined by using formula 10 . $\begin{gathered}\% \text { Floating } \\ \text { microspheres }\end{gathered}=\frac{\text { Weight floating microspheres } \times 100}{\text { The initial weight of floating microspheres }}$

In-vitro Drug Release Studies: The dissolution rate of the prepared beads was studied using USP rotating paddle dissolution apparatus II (Lab India). A known weight of beads containing an equivalent amount of $10 \mathrm{mg}$ of loratadine was placed in the dissolution medium (900 $\mathrm{ml}$ of buffer $\mathrm{pH} 1.2$ ). The temperature was adjusted to $37 \pm 0.5^{\circ} \mathrm{C}$ at $50 \mathrm{rpm}$. $5 \mathrm{ml}$ of samples were withdrawn at specified time intervals and replaced with fresh dissolution medium. The samples were filtered with $0.45 \mu \mathrm{m}$ Whatman membrane filter and the quantity of the drug released was determined using spectrophotometer at $214 \mathrm{~nm}$.

Kinetic Studies of Drug Release: The release data were analyzed using different kinetic equations which include zero-order, first-order kinetics, Higuchi diffusion, and Korsmeyer - Peppas models. The dissolution release kinetics and result of the best fit model among the preparations were also compared.

To study the mechanism of drug release from the optimized formulation of matrix tablets, the release data were fitted to the following equations:

$$
\text { Zero-order equation } Q_{t}=Q_{0}+k_{0} t
$$

Where, $\mathrm{Q}_{\mathrm{t}}$ is the amount of drug release in time $\mathrm{t}$, $\mathrm{Q}_{0}$ is the initial amount of drug in the solution (most times, $Q_{0}=0$ ) and $\mathrm{k}_{0}$ is the zero order release rate.

First-order equation $\ln Q_{t}=\ln Q_{0}+k_{l} t$

Where, $Q_{t}$ is the amount of drug released in time t, $\mathrm{Q}_{0}$ is the initial amount of drug in the solution, and $\mathrm{k}_{1}$ is the first order release rate constant.

$$
\text { Higuchi's equation (Higuchi, 1962), } Q=k_{H} t_{1 / 2}
$$

Where, $\mathrm{Q}$ is the amount of drug release at time $\mathrm{t}$, and $\mathrm{k}_{\mathrm{H}}$ is the Higuchi diffusion rate constant.

Korsmeyer et al.,'s equation

(Koresmeyer et al., 1983): $M_{t} / M_{\mu}=K_{n}$

Where $\mathbf{M}_{\mathrm{t}}$ is the amount of drug released at time $\mathrm{t}$, $\mathrm{M}_{\mu}$ is the amount of drug released after an infinite time, and $\mathrm{k}$ is a kinetic constant incorporating 
structural and geometric characteristics of the floating gel beads, and $\mathrm{n}$ is the diffusion exponent indicative of the drug release mechanism. The mechanism of drug release was dependent on the value of ' $n$ '.

Stability Studies: The stability of loratadine floating beads was studied at $25{ }^{\circ} \mathrm{C}$ and $60 \%$ relative humidity in closed high-density polyethylene bottles for 3 months. The drug content and the floating behavior were determined at different time intervals such as 1,2 and 3 months ${ }^{11}$.

\section{RESULTS AND DISCUSSION:}

Pre-Formulation Studies of Loratadine: The drug and the excipients interaction studies were evaluation by checking the physical appearance and by FT-IR analytical method.

The following pre-formulation studies were performed on loratadine and excipients.

\section{Analytical Report for API:}

TABLE 2: ANALYTICAL REPORT FOR LORATADINE

\begin{tabular}{cc}
\hline Pre-formulation test & Results \\
\hline Description & Colorless \\
Nature & Odorless \\
Description & Colorless, odorless crystalline powder \\
Solubility & Soluble in DMSO $(50 \mathrm{mg} / \mathrm{ml})$, ethanol \\
& $\left(77 \mathrm{mg} / \mathrm{ml}\right.$ at $\left.25^{\circ} \mathrm{C}\right)$, water $(<1 \mathrm{mg} / \mathrm{ml}$ \\
& at $\left.25^{\circ} \mathrm{C}\right)$, chloroform and methanol \\
Category & Antihistamine drug \\
Melting point & $128^{\circ} \mathrm{C}$ \\
\hline
\end{tabular}

\begin{tabular}{cc} 
TABLE 3: LORATADINE CHARACTERIZATION \\
\hline Test & Result \\
\hline Particle Size $(\mu \mathrm{m})$ & $10.35 \pm 0.40$ \\
Bulk Density $(\mathrm{g} / \mathrm{cc})$ & $0.457 \pm 0.02$ \\
Tapped Density $(\mathrm{g} / \mathrm{cc})$ & $0.539 \pm 0.02$ \\
Carr's Index & $18.58 \pm 0.04$ \\
Hausner's Ratio & $01.26 \pm 0.02$ \\
The angle of Repose $\left({ }^{\circ}\right)$ & $27.35 \pm 0.04$ \\
\hline
\end{tabular}

Drug-Polymer -Excipients Compatibility Studies: The interaction studies were carried out to ascertain any interaction of the drug with the excipients used in the preparation of floating gel beads.

\section{Interpretation of Loratadine:}

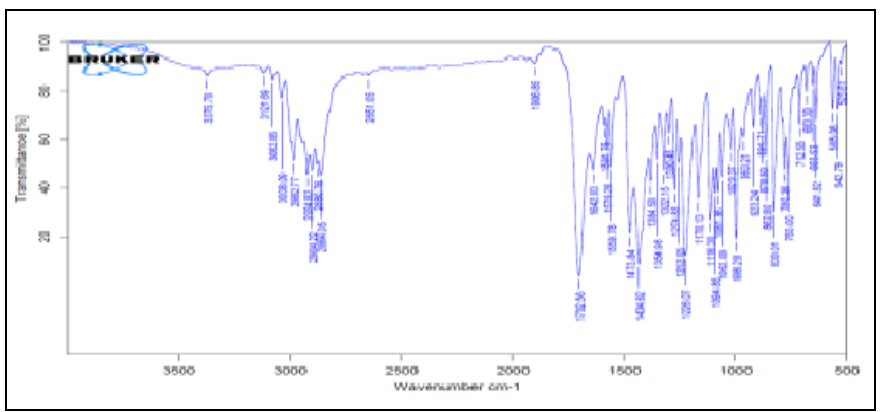

FIG. 1: FT-IR SPECTRA FOR LORATADINE PURE DRUG

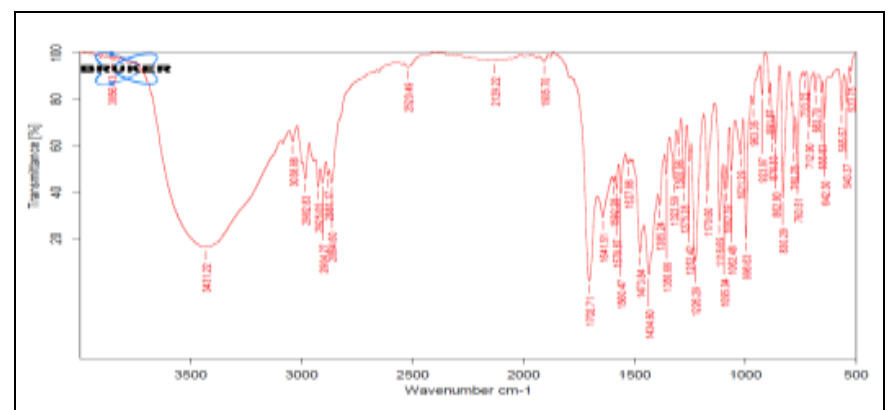

FIG. 2: FT-IR SPECTRA FOR FORMULATION F1

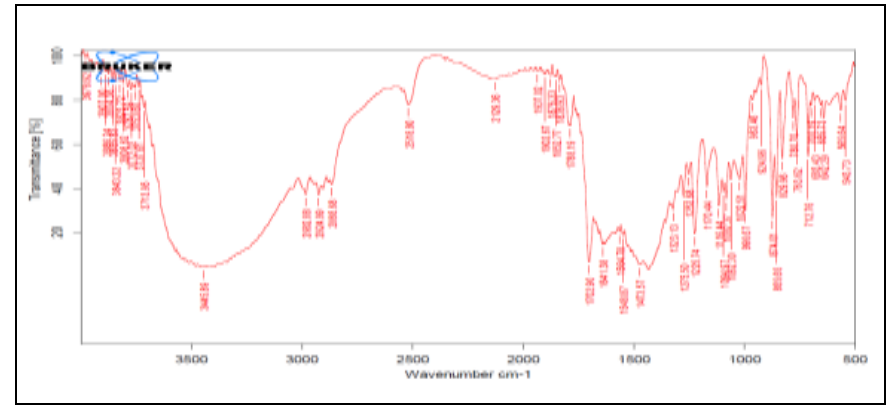

FIG. 4: FT-IR SPECTRA FOR FORMULATION F7

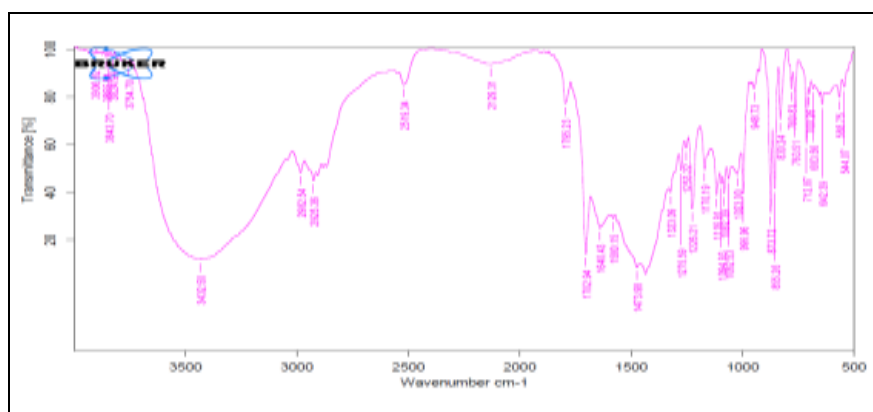

FIG. 3: FT-IR SPECTRA FOR FORMULATION F4

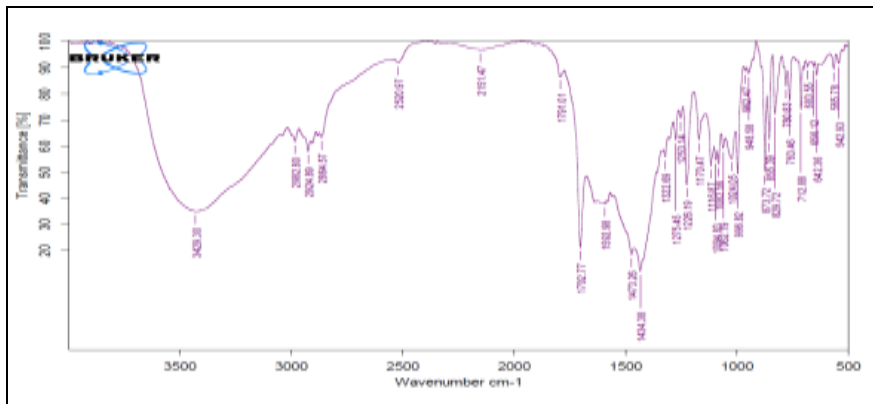

FIG. 5: FT-IR SPECTRA FOR FORMULATION F10 


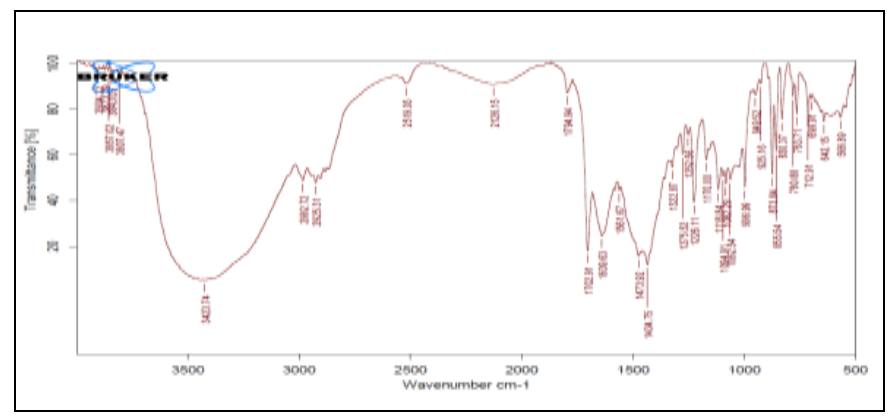

FIG. 6: FT-IR SPECTRA FOR FORMULATION F11

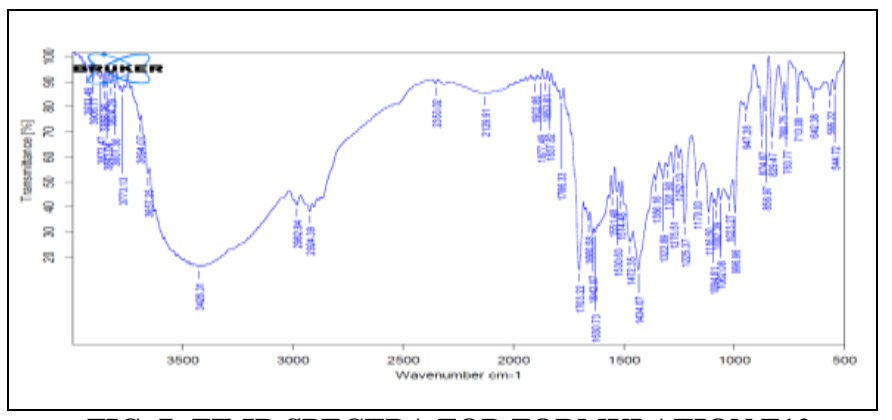

FIG. 7: FT-IR SPECTRA FOR FORMULATION F12

TABLE 4: FT-IR SPECTRA FOR LORATADINE AND LORATADINE FORMULATIONS

\begin{tabular}{cccccccc}
\hline Interpretation & Loratadine & \multicolumn{5}{c}{ IR absorption bands $\left(\mathbf{c m}^{-\mathbf{1}}\right)$} \\
\cline { 3 - 7 } & pure drug & F1 & F4 & F7 & F10 & F11 & F12 \\
\hline C=O stretching \& N-H bending & 1702.56 & 1702.71 & 1702.94 & 1702.90 & 1702.77 & 1702.91 & 1703.22 \\
C-Cl stretching & 996.28 & 996.63 & 996.96 & 996.67 & 996.82 & 996.99 & 996.96 \\
N=O stretching & 1434.62 & 1434.60 & 1473.98 & 1473.57 & 1434.38 & 1434.75 & 1434.07 \\
Saturated aliphatic \& side chain & 1226.07 & 1226.29 & 1226.21 & 1225.74 & 1226.19 & 1226.11 & 1225.37 \\
aromatic groups & & & & & & & \\
\hline
\end{tabular}

Based on FT-IR spectra obtained, it was evident that there was no significant interaction of loratadine with the carriers and other excipients.

\section{Formulation Development:}

Standard Curve of Loratadine: In the current study, loratadine in $\mathrm{pH} 1.2$ buffer showed good reproducibility in the concentration range of 5 $\mu \mathrm{g} / \mathrm{ml}-30 \mu \mathrm{g} / \mathrm{ml}$ at $214 \mathrm{~nm}$ as shown in Table 5 and Fig. 8. Correlation $\left(\mathrm{R}^{2}=0.999\right)$ between concentration and absorbance was found to be closer to 1 indicating that the method obeyed BeerLambert's Law.

TABLE 5: STANDARD CALIBRATION CURVE OF LORATADINE

\begin{tabular}{cc}
\hline $\begin{array}{c}\text { Concentration } \\
(\boldsymbol{\mu g} / \mathbf{m l})\end{array}$ & $\begin{array}{c}\text { Absorbance at 214 } \mathbf{~ n m} \\
\text { (in a buffer solution, } \mathbf{p H ~ 1 . 2})\end{array}$ \\
\hline 0 & 0 \\
5 & 0.201 \\
10 & 0.389 \\
15 & 0.569 \\
20 & 0.748 \\
25 & 0.929 \\
30 & 1.098 \\
\hline
\end{tabular}

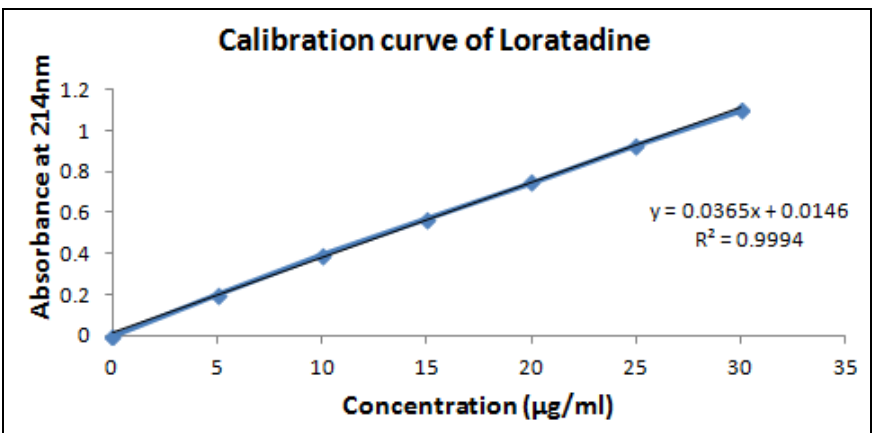

FIG. 8: STANDARD CALIBRATION CURVE OF LORATADINE IN pH 1.2 BUFFER
Preparation of Loratadine Floating Beads: Total twelve formulations of loratadine floating gel beads with the dose of $10 \mathrm{mg}$ were prepared by ionotropic gelation technique using polymers such as HPMC K4M, HPMC K15M, and Carbopol 934P and the resulting beads were shown in Fig. 9.

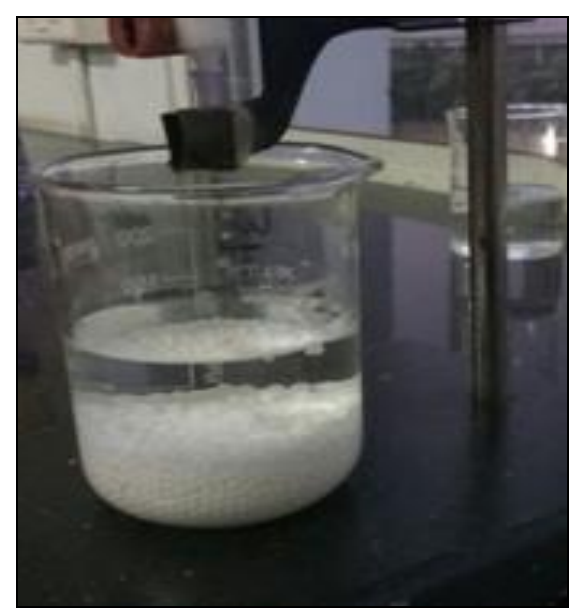

FIG. 9: PREPARATION OF LORATADINE FLOATING ALGINATE BEADS BY IONIC GELATION METHOD

Evaluation of Loratadine Floating Beads: The prepared beads were evaluated for particle size analysis, bulk density, tapped density, compressibility index, Hausner's ratio, the angle of repose, swelling index, drug entrapment efficiency \& \% yield, \% buoyancy, in-vitro drug release studies, kinetic modeling of drug release and Stability studies. 
Particle Size Analysis: The particle size of floating loratadine gel beads was affected by the amount of polymer used and its ratio concerning alginate in the formulations. The mean particle size of loratadine floating gel beads significantly increased with the increasing polymer concentration and found to be in the range from $725.23 \mu \mathrm{m} \pm 0.02$ to $929.09 \mu \mathrm{m} \pm 0.04$ as represented in Table 6. The effect of polymer type on the size of loratadine beads was observed to be in the following order and may be related to variations in the molecular weight as well as the structure of polymers that resulted in the polymeric solutions of different viscosities.

HPMC K4M > HPMC K15M > Carbopol 934P

Micromagnetic Properties of Loratadine Floating Gel Beads: All the formulations were evaluated for their micrometric properties as well as physical characteristics and found to be within the limits as shown in Table 6. The bulk density was found in the range of $0.48 \mathrm{~g} / \mathrm{cm}^{3} \pm 0.14-0.79$ $\mathrm{g} / \mathrm{cm}^{3} \pm 0.34$. The tapped density ranged between $0.54 \mathrm{~g} / \mathrm{cm}^{3} \pm 0.16-0.79 \mathrm{~g} / \mathrm{cm}^{3} \pm 0.42$. Carr's index of all the formulations existed in the range of 08.75 \pm 0.03 to $15.38 \pm 0.04$. The result of the Hausner's ratio of all the formulations was between $1.00 \pm$ 0.01 and $1.19 \pm 0.01$. The angle of repose of all formulations was within the range of $25.02^{\circ} \pm 0.27$ to $27.78^{\circ} \pm 0.12$. These values indicate that the powder blend exhibited good flow properties. These values indicate that the prepared loratadine floating beads exhibited good flow properties. Based on the results obtained, formulation F7 was found to be the best formulation compared to other formulations.

TABLE 6: MEAN PARTICLE SIZE AND MICROMERETIC PROPERTIES OF LORATADINE FLOATING GEL BEADS

\begin{tabular}{|c|c|c|c|c|c|c|}
\hline $\begin{array}{l}\text { Formula } \\
\text { code }\end{array}$ & $\begin{array}{l}\text { Mean particle } \\
\text { size }(\mu \mathrm{m})\end{array}$ & $\begin{array}{l}\text { Bulk density } \\
\left(\mathrm{g} / \mathrm{cm}^{3}\right)\end{array}$ & $\begin{array}{c}\text { Tapped } \\
\text { density }\left(\mathrm{g} / \mathrm{cm}^{3}\right)\end{array}$ & $\begin{array}{l}\text { Carr's } \\
\text { index }\end{array}$ & $\begin{array}{c}\text { Hausner's } \\
\text { ratio }\end{array}$ & $\begin{array}{l}\text { Angle of } \\
\text { repose }\left(^{\circ}\right)\end{array}$ \\
\hline $\mathrm{F} 2$ & $693.57 \pm 0.06$ & $0.48 \pm 0.14$ & $0.54 \pm 0.16$ & $14.28 \pm 0.36$ & $1.12 \pm 0.01$ & $26.65 \pm 0.27$ \\
\hline $\mathrm{F} 4$ & $752.22 \pm 0.06$ & $0.48 \pm 0.35$ & $0.56 \pm 0.12$ & $14.28 \pm 0.35$ & $1.16 \pm 0.01$ & $26.32 \pm 0.24$ \\
\hline F5 & $785.97 \pm 0.02$ & $0.54 \pm 0.17$ & $0.62 \pm 0.44$ & $12.90 \pm 0.34$ & $1.15 \pm 0.005$ & $27.78 \pm 0.12$ \\
\hline F6 & $728.28 \pm 0.04$ & $0.52 \pm 0.07$ & $0.60 \pm 0.04$ & $15.38 \pm 0.04$ & $1.15 \pm 0.01$ & $26.42 \pm 0.36$ \\
\hline F8 & $692.05 \pm 0.09$ & $0.60 \pm 0.16$ & $0.68 \pm 0.15$ & $13.79 \pm 0.22$ & $1.13 \pm 0.015$ & $26.75 \pm 0.35$ \\
\hline F9 & $657.84 \pm 0.07$ & $0.71 \pm 0.48$ & $0.74 \pm 0.24$ & $12.34 \pm 0.41$ & $1.04 \pm 0.005$ & $25.42 \pm 0.12$ \\
\hline F10 & $729.56 \pm 0.11$ & $0.70 \pm 0.18$ & $0.76 \pm 0.14$ & $11.90 \pm 0.34$ & $1.09 \pm 0.01$ & $26.35 \pm 0.42$ \\
\hline F11 & $929.09 \pm 0.04$ & $0.68 \pm 0.22$ & $0.75 \pm 0.16$ & $10.76 \pm 0.11$ & $1.10 \pm 0.005$ & $27.18 \pm 0.25$ \\
\hline F12 & $884.37 \pm 0.06$ & $0.53 \pm 0.27$ & $0.60 \pm 0.26$ & $11.66 \pm 0.12$ & $1.13 \pm 0.005$ & $26.53 \pm 0.19$ \\
\hline
\end{tabular}

Swelling Studies: The swelling behavior of the all prepared loratadine floating beads remained intact in pH 1.2 buffer during the experimental time and observed to appear white. From the results of the swelling study, it was evident that the swelling ratios found to increase with the increasing polymer concentrations as shown in Table 7 and Fig. 10. Polymers used may be placed in the following order as per their swelling ratios in $\mathrm{pH}$ 1.2 buffer as followed:

\section{Carbopol 934P > HPMC K15M > HPMC K4M}

Percentage Drug Entrapment Efficiency: From the results, it was evident that the drug encapsulation efficiency was found to be low for the loratadine floating gel bead formulation F1, while the values were significantly increased with the increasing concentration of the polymer HPMC $\mathrm{K} 4 \mathrm{M}$ as shown in Table 7. Further, the results of the study showed that the encapsulation efficiencies were dependent on the type as well as the concentration of polymer used in the preparation of loratadine floating gel beads.

The results were also dependent on the viscosity of the polymer used, the diffusion of loratadine from the gel beads decreased as the viscosity increased.

Percentage Yield: The $\%$ yield of loratadine floating gel beads ranged from $84.12 \% \pm 1.25$ to $92.51 \% \pm 1.35$ for formulations $\mathrm{F} 1$ and $\mathrm{F} 12$ respectively. Based on the results obtained, it was observed that the yield increased with the increase in polymer concentration and polymer type. 
Percentage Drug Loading: The \% drug loading of different beads was ranged from $79.25 \% \pm 1.16$ to $95.85 \% \pm 1.27$ for formulations $\mathrm{F} 1$ to F12. The $\%$ encapsulation efficiency was found to be highest for formulation $\mathrm{F} 7$, i.e. $95.85 \% \pm 1.27$.
Percentage Buoyancy: The results showed that all developed loratadine floating beads had \% buoyancy from $79.40 \% \pm 1.65$ to $96.19 \% \pm 1.12$ of beads remained floated for $12 \mathrm{~h}$.

TABLE 7: RESULTS OF SWELLING STUDY OF LORATADINE FLOATING GEL BEAD FORMULATIONS

\begin{tabular}{cccccc}
\hline $\begin{array}{c}\text { Formulation } \\
\text { code }\end{array}$ & $\begin{array}{c}\text { Swelling } \\
\text { index (\%) }\end{array}$ & $\begin{array}{c}\text { Drug entrapment } \\
\text { efficiency }(\boldsymbol{\%})\end{array}$ & $\begin{array}{c}\text { Percentage } \\
\text { yield }\end{array}$ & $\begin{array}{c}\text { \% Drug } \\
\text { loading }\end{array}$ & $\begin{array}{c}\text { \% } \\
\text { Buoyancy }\end{array}$ \\
\hline F1 & $75.52 \pm 1.25$ & $78.12 \pm 1.05$ & $84.12 \pm 1.25$ & $79.25 \pm 1.16$ & $86.22 \pm 0.96$ \\
F2 & $78.49 \pm 1.08$ & $80.47 \pm 0.96$ & $89.68 \pm 1.19$ & $81.09 \pm 0.63$ & $85.65 \pm 1.25$ \\
F3 & $82.41 \pm 0.98$ & $83.68 \pm 1.26$ & $90.49 \pm 1.35$ & $82.15 \pm 1.54$ & $84.26 \pm 1.32$ \\
F4 & $84.96 \pm 0.87$ & $86.25 \pm 1.34$ & $82.27 \pm 0.86$ & $85.27 \pm 1.31$ & $92.15 \pm 1.06$ \\
F5 & $87.64 \pm 1.14$ & $91.62 \pm 0.89$ & $89.65 \pm 0.66$ & $91.36 \pm 0.72$ & $82.67 \pm 1.18$ \\
F6 & $88.35 \pm 1.35$ & $92.36 \pm 1.09$ & $90.43 \pm 1.29$ & $91.29 \pm 1.11$ & $88.48 \pm 1.34$ \\
F7 & $89.47 \pm 0.84$ & $96.30 \pm 1.28$ & $92.51 \pm 1.35$ & $95.85 \pm 1.27$ & $96.19 \pm 1.12$ \\
F8 & $83.24 \pm 0.79$ & $85.75 \pm 1.46$ & $90.26 \pm 1.08$ & $84.26 \pm 1.05$ & $78.54 \pm 1.07$ \\
F9 & $85.05 \pm 1.26$ & $84.59 \pm 0.85$ & $88.05 \pm 1.24$ & $83.45 \pm 0.76$ & $79.82 \pm 1.16$ \\
F10 & $87.19 \pm 1.08$ & $83.08 \pm 0.78$ & $85.57 \pm 1.05$ & $82.48 \pm 0.37$ & $79.40 \pm 1.65$ \\
F11 & $88.36 \pm 0.88$ & $85.66 \pm 1.12$ & $87.92 \pm 1.63$ & $84.28 \pm 1.61$ & $86.26 \pm 1.38$ \\
F12 & $90.65 \pm 0.65$ & $86.29 \pm 0.66$ & $87.34 \pm 1.51$ & $85.35 \pm 0.42$ & $91.35 \pm 1.46$ \\
\hline
\end{tabular}

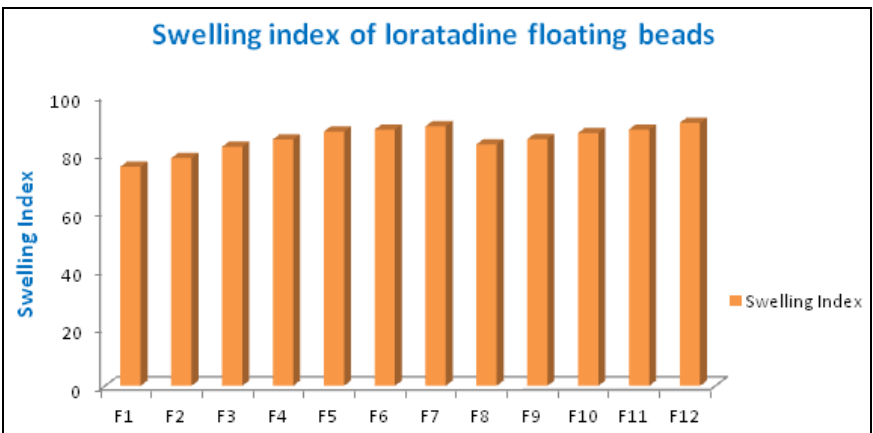

FIG. 10: SWELLING STUDY OF LORATADINE FLOATING GEL BEADS

SEM of Floating Loratadine Beads: The SEM image for the optimized formulation of loratadine floating gel beads was shown in Fig. 11. SEM graph of beads showed that the beads were spherical with a uniform texture and slightly smooth surface. The slightly smooth surface was due to the use of optimum concentration ratio of sodium bicarbonate as a gas forming agent to sodium alginate $(1: 1 \mathrm{w} / \mathrm{w})$ for the bead formation.

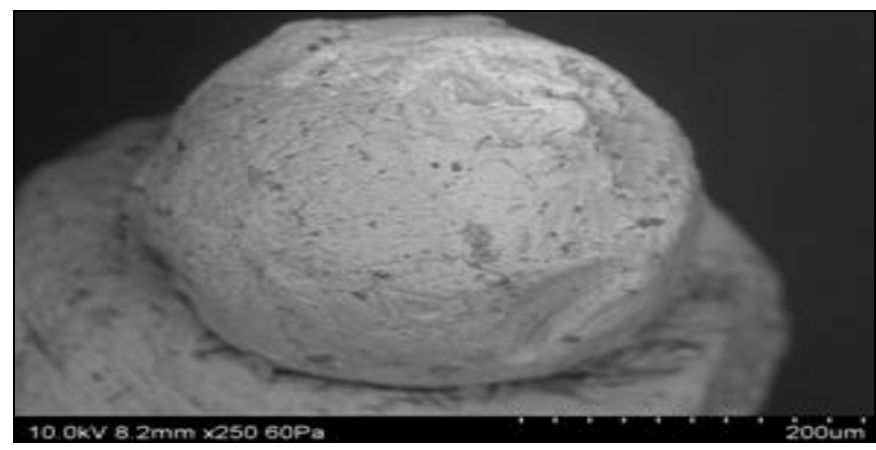

FIG. 11: SEM IMAGE OF LORATADINE FLOATING GEL BEAD FORMULATION F7

In-vitro Drug Release Studies: Loratadine floating gel beads were evaluated for in-vitro drug release studies in $\mathrm{pH} 1.2$ buffer, and the results were presented in Table 8 and 9.

The formulation F7 showed best drug release of $98.85 \% \pm 0.15$ within $12 \mathrm{~h}$ when compared to other formulations.

TABLE 8: IN-VITRO CUMULATIVE \% DRUG RELEASE OF LORATADINE BEADS F1 TO F6

\begin{tabular}{ccccccc}
\hline Time (h) & F1 & F2 & F3 & F4 & F5 & F6 \\
\hline 0 & 0 & 0 & 0 & 0 & 0 & $09.75 \pm 0.18$ \\
1 & $10.68 \pm 0.18$ & $08.45 \pm 0.17$ & $09.64 \pm 0.15$ & $08.99 \pm 0.20$ & $09.24 \pm 0.19$ & $17.86 \pm 0.14$ \\
2 & $19.58 \pm 0.06$ & $16.68 \pm 0.12$ & $17.56 \pm 0.09$ & $16.99 \pm 0.18$ & $17.14 \pm 0.14$ \\
3 & $28.11 \pm 0.14$ & $24.54 \pm 0.09$ & $26.15 \pm 0.12$ & $24.99 \pm 0.19$ & $26.21 \pm 0.17$ & $25.01 \pm 0.12$ \\
4 & $39.55 \pm 0.11$ & $31.68 \pm 0.11$ & $32.24 \pm 0.18$ & $30.59 \pm 0.14$ & $35.12 \pm 0.19$ & $33.58 \pm 0.09$ \\
5 & $48.69 \pm 0.09$ & $40.01 \pm 0.08$ & $41.02 \pm 0.09$ & $39.99 \pm 0.09$ & $43.32 \pm 0.11$ & $41.36 \pm 0.18$ \\
6 & $60.01 \pm 0.08$ & $48.23 \pm 0.05$ & $49.31 \pm 0.05$ & $48.68 \pm 0.06$ & $51.36 \pm 0.09$ & $49.07 \pm 0.19$ \\
7 & $69.10 \pm 0.10$ & $57.99 \pm 0.06$ & $58.42 \pm 0.14$ & $59.68 \pm 0.11$ & $59.98 \pm 0.10$ & $58.36 \pm 0.11$ \\
8 & $75.12 \pm 0.07$ & $65.28 \pm 0.12$ & $64.58 \pm 0.16$ & $65.32 \pm 0.12$ & $64.89 \pm 0.08$ & $66.01 \pm 0.15$ \\
9 & $81.54 \pm 0.11$ & $72.15 \pm 0.05$ & $71.56 \pm 0.09$ & $72.15 \pm 0.18$ & $73.12 \pm 0.09$ & $75.02 \pm 0.19$ \\
10 & $88.72 \pm 0.12$ & $79.13 \pm 0.16$ & $78.99 \pm 0.11$ & $79.25 \pm 0.10$ & $80.01 \pm 0.14$ & $80.36 \pm 0.09$ \\
11 & $94.21 \pm 0.14$ & $87.12 \pm 0.04$ & $86.59 \pm 0.16$ & $87.32 \pm 0.05$ & $88.12 \pm 0.16$ & $89.01 \pm 0.05$ \\
12 & $95.12 \pm 0.09$ & $94.58 \pm 0.11$ & $93.99 \pm 0.10$ & $94.02 \pm 0.07$ & $93.01 \pm 0.15$ & $94.01 \pm 0.09$ \\
\hline
\end{tabular}


TABLE 9: IN-VITRO CUMULATIVE \% DRUG RELEASE OF LORATADINE BEADS F7 TO F12

\begin{tabular}{ccccccc}
\hline Time (h) & F7 & F8 & F9 & F10 & F11 & F12 \\
\hline 0 & 0 & 0 & 0 & 0 & 0 & 0 \\
1 & $08.65 \pm 0.19$ & $09.98 \pm 0.18$ & $10.01 \pm 0.15$ & $10.26 \pm 0.11$ & $09.98 \pm 0.15$ & $10.21 \pm 0.16$ \\
2 & $13.23 \pm 0.15$ & $14.01 \pm 0.14$ & $14.23 \pm 0.13$ & $14.69 \pm 0.18$ & $15.01 \pm 0.13$ & $14.99 \pm 0.09$ \\
3 & $18.15 \pm 0.09$ & $18.99 \pm 0.16$ & $18.56 \pm 0.18$ & $19.65 \pm 0.16$ & $18.99 \pm 0.19$ & $19.01 \pm 0.12$ \\
4 & $20.12 \pm 0.05$ & $20.56 \pm 0.09$ & $20.23 \pm 0.11$ & $22.12 \pm 0.09$ & $21.06 \pm 0.16$ & $22.01 \pm 0.18$ \\
5 & $31.21 \pm 0.11$ & $30.99 \pm 0.05$ & $29.65 \pm 0.09$ & $33 . .32 \pm 0.12$ & $31.65 \pm 0.09$ & $32.01 \pm 0.13$ \\
6 & $39.99 \pm 0.15$ & $38.23 \pm 0.13$ & $39.45 \pm 0.05$ & $44.19 \pm 0.15$ & $40.01 \pm 0.05$ & $42.21 \pm 0.05$ \\
7 & $49.51 \pm 0.17$ & $50.12 \pm 0.11$ & $51.01 \pm 0.13$ & $52.00 \pm 0.06$ & $51.99 \pm 0.11$ & $52.01 \pm 0.09$ \\
8 & $60.01 \pm 0.08$ & $59.65 \pm 0.08$ & $60.23 \pm 0.07$ & $60.99 \pm 0.09$ & $61.01 \pm 0.16$ & $60.98 \pm 0.16$ \\
9 & $68.33 \pm 0.15$ & $68.77 \pm 0.13$ & $69.33 \pm 0.16$ & $71.95 \pm 0.12$ & $72.01 \pm 0.09$ & $71.65 \pm 0.07$ \\
10 & $75.32 \pm 0.06$ & $74.36 \pm 0.08$ & $75.32 \pm 0.18$ & $81.99 \pm 0.09$ & $80.12 \pm 0.15$ & $80.01 \pm 0.16$ \\
11 & $85.12 \pm 0.12$ & $84.32 \pm 0.11$ & $85.96 \pm 0.12$ & $91.32 \pm 0.11$ & $92.01 \pm 0.06$ & $91.99 \pm 0.19$ \\
12 & $98.85 \pm 0.15$ & $94.56 \pm 0.05$ & $94.01 \pm 0.11$ & $96.01 \pm 0.05$ & $96.32 \pm 0.19$ & $95.22 \pm 0.15$ \\
\hline
\end{tabular}

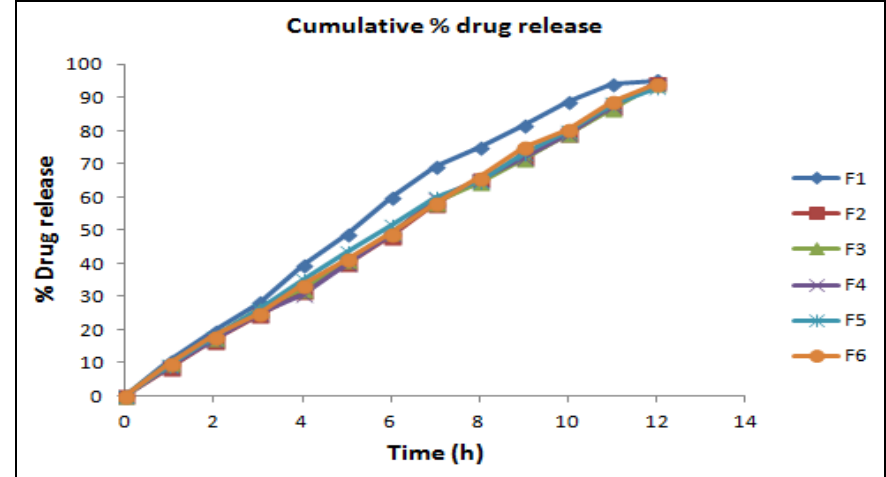

FIG. 12: IN-VITRO DRUG RELEASE PROFILES OF FORMULATIONS F1 - F6

\section{Kinetic Studies of Drug Release:}

Release Order Kinetics of Optimized Formulation of Floating Gel Beads: To determine the drug release mechanism; the data of the in-vitro drug release of all developed loratadine formulations (F1-F12) were fitted in various kinetic models such as zero, first order, Higuchi and Korsmeyer-Peppas models. The kinetic rate constant $(\mathrm{k})$ the coefficient of determination $\left(\mathrm{R}^{2}\right)$ were computed and were depicted in Table 10. The best fit with the highest coefficient of determination $\left(\mathrm{R}^{2}\right)$ for all formulae was shown with the Higuchi model followed by Peppas release model and then zero-order equation. These results revealed that the kinetic release pattern was best

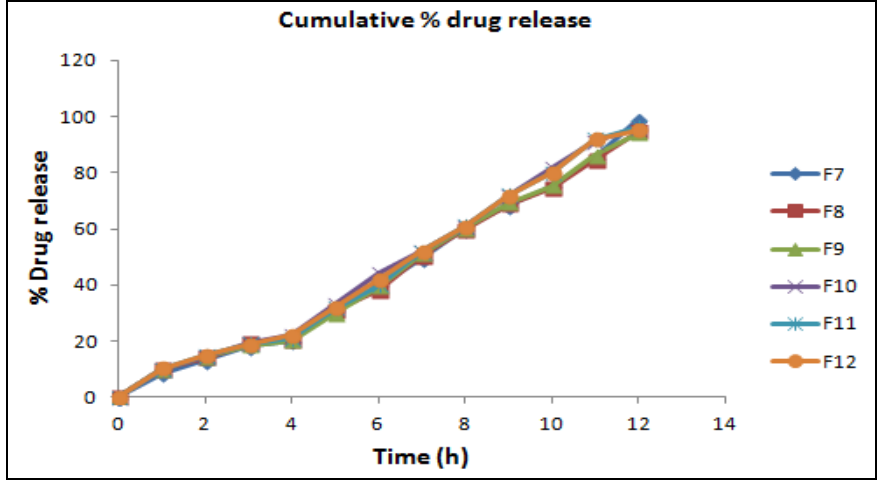

FIG. 13: IN-VITRO DRUG RELEASE PROFILES OF FORMULATIONS F7 - F12

fitted to Higuchi equation which describes drug release from a polymeric system by the mechanism of diffusion. Fickian diffusion mechanism of release was the drug release controlling mechanism for the optimized formulation F7. The in-vitro drug release profiles from optimized formulations F7 were applied on different kinetic models. The best fit with the highest correlation coefficient was observed in zero order and Higuchi model, indicating a diffusion controlled principle. Moreover, the ' $n$ ' value obtained from the Korsmeyer - Peppas plot, i.e. 0.825 suggested that the drug release from loratadine floating gel beads was by an anomalous non-fickian diffusion mechanism.

TABLE 10: DRUG RELEASE KINETICS FOR OPTIMIZED FORMULATION F7

\begin{tabular}{ccccccccc}
\hline \multirow{2}{*}{$\begin{array}{c}\text { Formulation } \\
\text { Code }\end{array}$} & \multicolumn{2}{c}{ Zero Order } & \multicolumn{2}{c}{ First Order } & \multicolumn{2}{c}{ Higuchi } & \multicolumn{2}{c}{ Korsmeyer -Peppas } \\
\cline { 2 - 9 } & $\mathbf{R}^{2}$ & $\mathbf{K}$ & $\mathbf{R}^{2}$ & $\mathbf{K}$ & $\mathbf{R}^{2}$ & $\mathbf{K}$ & $\mathbf{R}^{2}$ & $\mathbf{n}$ \\
\hline F7 & 0.983 & 8.090 & 0.650 & 0.108 & 0.860 & 29.26 & 0.966 & 0.825 \\
\hline
\end{tabular}

Stability Studies: The optimized loratadine floating bead formulation F7 was subjected to stability studies at $25^{\circ} \mathrm{C} / 60 \% \mathrm{Rh}$ for 3 months. After storage under these conditions, loratadine floating gel beads were analyzed for the change in physical appearance, drug content, and floating behavior. Results of stability study indicated that there were no significant changes in the physical characteristics of the optimized formulation $\mathrm{F} 7$ concerning color and shape by the visual 
examination. The drug content of the floating beads also did not alter until the end of 3 months after storage. In the case of floating behavior also, it was found that there was no change in lag time and the floating time was more than $12 \mathrm{~h}$.
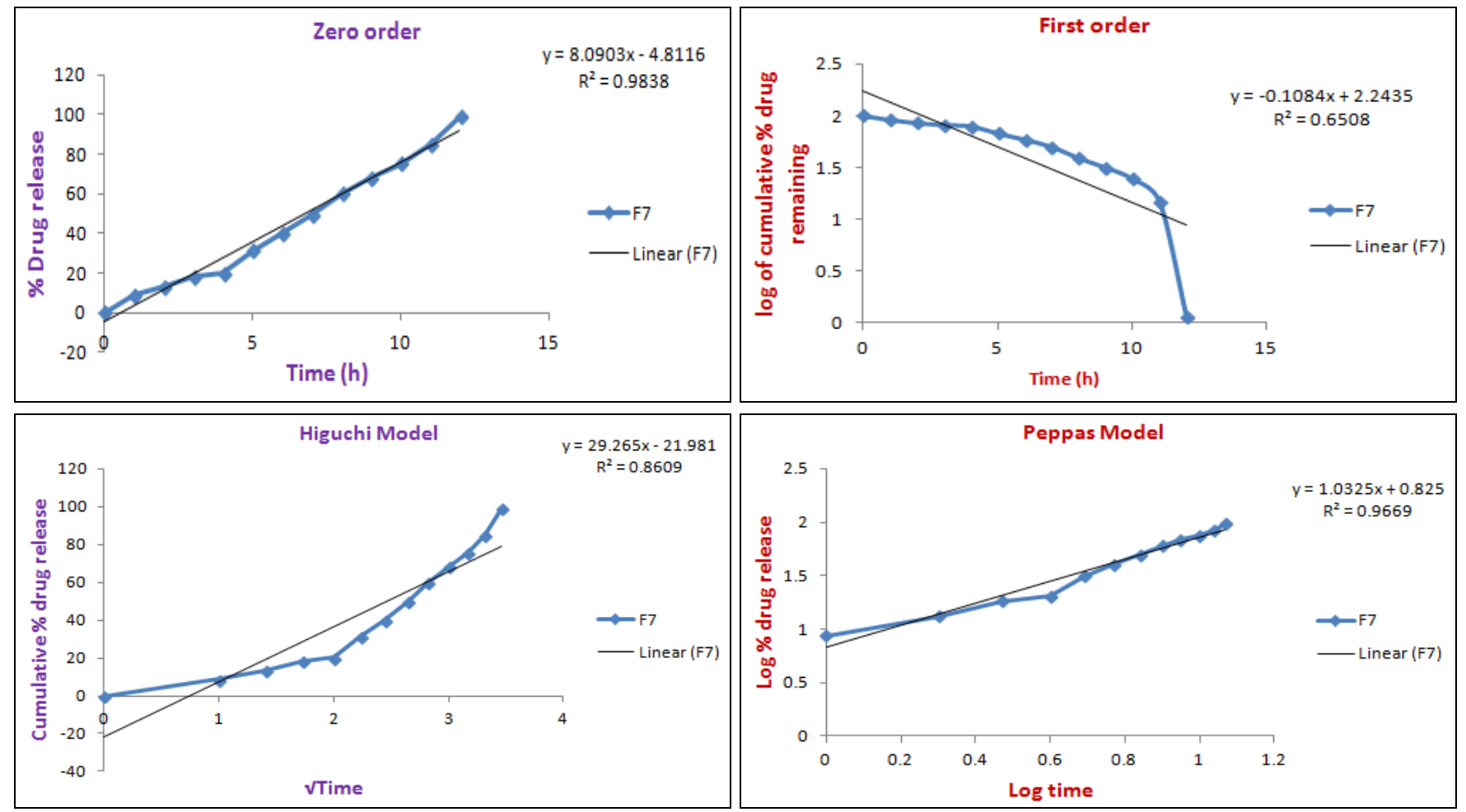

FIG. 14: DRUG RELEASE KINETICS OF OPTIMIZED FORMULATION F7

TABLE 11: EVALUATION OF OPTIMIZED LORATADINE FLOATING BEADS (F7) AFTER SHORT TERM STABILITY PERIOD

\begin{tabular}{ccc}
\hline Parameters & Before & After \\
\hline In-vitro Drug release (\%) & $98.37 \pm 0.02$ & $98.05 \pm 0.08$ \\
Floating lag time (min) & $7.4 \pm 0.2$ & $7.4 \pm 0.1$ \\
Floating time (h) & $>12$ & $>12$ \\
\hline $\mathrm{n}=3$; values are expressed as mean $\pm \mathrm{SD}$ &
\end{tabular}

CONCLUSION: In the current research study, floating beads of loratadine were formulated using different polymers in different proportions by ionic gelation technique to achieve sustained release of the drug. The sodium alginate beads prepared with hydroxyl propyl methyl cellulose (HPMC) K15M in higher concentration, i.e., formulation F7 showed comparatively better drug loading and floating characteristics. The in-vitro drug release studies proved that the gel beads exhibited sustained drug release.

ACKNOWLEDGEMENT: The authors are grateful to the Management of Vijaya Institute of Pharmaceutical Sciences for Women, Enikepadu, Vijayawada for providing the necessary facilities to carry out the research work.
CONFLICT OF INTEREST: The authors declare that they have no conflicts of interest.

\section{REFERENCES:}

1. Arora S, Ali A, Ahuja A, Khar RK and Baboota S: Floating drug delivery systems: a review. AAPS Pharm Sci Tech 2005; 6(3): E372-E390.

2. Yeole PG, Khan S and Patel VF: Floating drug delivery system: need and development. Indian J Pharm Sci 2005; 67: 265-272.

3. Goodman and Gilman's The Pharmacological Basis of Therapeutics, $10^{\text {th }}$ ed; McGraw-Hill, New York 2006: 638639.

4. Talukder $\mathrm{R}$ and Fassihi R: Gastro retentive delivery systems: hollow beads. Drug Dev Ind Pharm 2004; 30: 405-412.

5. Torrado JJ and Augsberger LL: Tableting of multiparticulate modified release systems. In: Pharmaceutical Dosage Forms - Tablets Vol. 2. Rational Design and Formulation (Augsberger LL and Hoag SW, eds.), Edi 3, Informa Healthcare, London 2008: 509-533.

6. Whitehead L, Fell JT, Collett JH, Sharma HL and Smith A. In-vivo study demonstrating prolonged gastric retention. J Control Release 1998; 55: 3-12.

7. Whitehead L, Collett JH and Fell JT: Amoxycillin release from a floating dosage form based on alginates. Int $\mathrm{J}$ Pharm 2000; 210: 45-49.

8. Ichikawa M, Watanabe S and Miyake Y: A new multipleunit oral floating dosage system. II: in-vivo evaluation of floating and sustained-release characteristics with paraamino benzoic acid and isosorbide dinitrate as model drugs. J Pharm Sci 1991; 80: 1153-1156. 
9. Bulgarelli E, Forni $\mathrm{F}$ and Bernabei MT: Effect of matrix composition and process conditions on casein gelatin beads floating properties. Int J Pharm 2000; 198: 157-165.

10. Srivastava A, Ridhurkar K and Wadhwa DN: Floating microspheres of cimetidine: formulation, characterization and in-vitro evaluation. Acta Pharm 2005; 55: 277-285.

11. El-Kamel AH, Sokar MS, Al Gamal SS and Naggar VF: Preparation and evaluation of ketoprofen floating oral drug delivery system. Int J Pharm 2001; 220: 13-21.

\section{How to cite this article:}

Begum SA, Jhansi J and Padmalatha K: Formulation and evaluation of floating gel beads of loratadine. Int J Pharm Sci \& Res 2019; 10(3): 1289-99. doi: 10.13040/IJPSR.0975-8232.10(3).1289-99.

All @ 2013 are reserved by International Journal of Pharmaceutical Sciences and Research. This Journal licensed under a Creative Commons Attribution-NonCommercial-ShareAlike 3.0 Unported License.

This article can be downloaded to Android OS based mobile. Scan QR Code using Code/Bar Scanner from your mobile. (Scanners are available on Google Play store) 